\title{
Ética na Gestão: o disCURSO ORGANIZACIONAL E A PERCEPÇÃO DOS GESTORES
}

\author{
Ethics in Management: speech perception of organizational \\ and managers
}

\section{Mário Cesar Barreto Moraes}

Professor do Programa de Pós-Graduação em Administração, Universidade do Estado de Santa Catarina - Florianópolis - SC, Brasil. E-mail: mcbmstrategos@gmail.com

Alice Carneiro de Castro

Mestre em Administração de Empresas, Universidade do Estado de Santa Catarina - Florianópolis - SC, Brasil.

E-mail: alice_adm@yahoo.com.br

Gilberto de Oliveira Moritz

Professor do Programa de Pós-Graduação em Administração, Universidade Federal de Santa Catarina - Florianópolis - SC, Brasil.

E-mail: gomoritz@cse.ufsc.br

Marcus Vinícius Andrade de Lima

Professor do Programa de Pós-Graduação em Administração, Universidade Federal de Santa Catarina - Florianópolis - SC, Brasil.

E-mail: marcus.lima@cse.ufsc.br

\section{Resumo}

Desde os filósofos gregos têm-se estudado o comportamento humano e seus princípios. Na Modernidade, com o advento das organizações, a preocupação em controlar e prever este comportamento superou a importância da ética e moral, instituindo-se cada vez mais códigos regulatórios de conduta, tendo a racionalidade funcional como base. Porém, não é claro se os gestores das organizações compartilham desses pensamentos e se o discurso organizacional converge com o pessoal. Portanto, esta pesquisa teve por objetivo analisar a convergência entre o discurso organizacional e a percepção dos executivos das indústrias vencedoras do Prêmio Catarinense de Excelência de 2006 a 2010. Foram analisadas as declarações institucionais e realizadas entrevistas com os executivos e concluiu-se que a racionalidade instrumental e os conceitos da Modernidade são determinantes, sendo a percepção dos gestores e o conteúdo dos documentos organizacionais convergentes e com alto grau de coerência.

Palavras-chave: Ética. Racionalidade. PósModernidade. Comportamento Organizacional.

\section{Abstract}

Since the Greek philosophers have been studying human behavior and its principles. In modernity, with the advent of organizations, the concern to control and predict this behavior surpassed the importance of ethics and morality, instituting increasingly regulatory codes of conduct, and functional rationality as a basis. However, it is unclear whether the managers of these organizations share thoughts and organizational discourse converges with the staff. Therefore, this study aimed to analyze the convergence of organizational discourse and the perception of senior executives in industries that won the Award of Excellence Santa Catarina from 2006 to 2010 . We analyzed the institutional statements and interviews with executives and found that the instrumental rationality of modernity and concepts are crucial, and the perception of managers and content of organizational documents and converged with a high degree of consistency.

Key words: Ethics. Rationality. Post-Modernity. Organizational Behavior. 


\section{INTRODUÇÃO}

A preocupação com a delimitação do próprio comportamento individual e grupal remete o estudo da ética e da moral, principalmente aos gregos (SINGER, 2000). Filósofos e pensadores elaboraram tratados sobre a Ética no relacionamento interpessoal e na consciência humana. Com o tempo foi intensificada a construção de deveres morais legais com sistemas de recompensas e punições, padronizando o comportamento considerado ético, destacando-se para Singer (2000), os tratados de Hobbes e de Rousseau.

Com o advento do capitalismo e da industrialização, culminou-se na normatização do comportamento esperado pelas pessoas na sociedade. Abandonou-se o sentido de transcendência da ética, de exercer suas virtudes e a dimensão de um ser humano mais completo - perfeito subjetivamente - ficando apenas com a imanência das normas e regras morais impostas pela sociedade e pelas instituições. (BOFF, 2003)

Tais regras ou normas passaram a permear e se evidenciar na vida das organizações, caracterizados na elaboração de códigos de comportamento cognominados de Ética, visando regular em maior ou menor grau as relações dentro e fora das próprias organizações. Alternando-se as denominações, esses regulamentos tornaram-se conhecidos nas empresas desde a amplitude de um "Código de Ética" até o reducionismo de um "Código de Conduta". Esta pesquisa pretende identificar tal realidade considerando o nível de convergência entre a prática do regramento de conduta nas organizações e a convergência desse discurso com a percepção ética do gestor organizacional, abstraindose um quadro de racionalidade e o contexto em que se insere.

Ramos (2001) apresentou questionamentos acerca da prática da gestão, arguindo quanto ao avanço para além do ponto da racionalidade funcional, da síndrome comportamentalista e, se os novos modelos de gestão prezam pela subjetividade nas organizações, relevando as percepções das pessoas ou o formalismo prescritivo documental.

Numa perspectiva reducionista, não raras vezes, são apenas pessoas cumprindo os deveres, sem realmente refletir sobre o certo e o errado, apenas se comportando como, mas não necessariamente sendo éticas (MENDONÇA, 2003). A diferença entre comportar-se e ser é destacada por Ramos (1981), quando afirma que o mundo passa por uma síndrome comportamental, em que se é exigido do ser humano um comportamento padrão, um sucesso modelado, enfim, ele não é o que ele é, mas o que os outros querem que seja.

Para selecionar a amostra objeto da pesquisa, considerou-se que em Santa Catarina há um processo anual de seleção de organizações tidas como de referência no que tange a gestão organizacional, tomando-se por base o Modelo de Excelência da Gestão (MEG). Esse processo é conhecido como Prêmio Catarinense de Excelência (PCE) e ocorre desde 2005. Um dos requisitos do MEG trata sobre a atuação ética da organização em seus relacionamentos com as partes interessadas e como são formalizados e acompanhados os princípios éticos válidos para a organização. (MOVIMENTO..., 2009)

Desde o início desse processo de avaliação $e$ de premiação, foram reconhecidas 17 organizações catarinenses como referência em gestão organizacional. Dessas organizações, três são do setor industrial, setor referência e representativo em Santa Catarina e pouco identificado entre as vencedoras de prêmios e reconhecimentos que utilizam o MEG (MOVIMENTO..., 2011). Pode-se então considerar essas organizações como efetivas referências em gestão organizacional, integrando assim a população deste estudo, tendo por amostra uma organização de pequeno porte, outra de médio porte e uma terceira, multinacional de grande porte.

De conformidade com os resultados do prêmio, nas empresas pesquisadas, a expectativa de ação dos colaboradores, por parte da organização, via de regra, tem sido evidenciada no código regulatório, o qual pode convergir ou não com o padrão ético do indivíduo, revelando uma tensão neste relacionamento. Neste sentido, caracterizou-se o objetivo geral da pesquisa: Analisar a convergência entre o discurso organizacional e a percepção da ética pelos executivos das indústrias vencedoras do Prêmio Catarinense de Excelência de 2006 a 2010. Na expectativa de alcançar o objetivo, a pesquisa teve por foco os dados primários e secundários das três organizações que integram o conjunto amostral, reconhecidas pelo Modelo de Excelência da Gestão. 


\section{Referencial Teórico}

\section{A razão é}

[...] a força que liberta dos preconceitos, do mito, das opiniões enraizadas, mas falsas $e$ das aparências, permitindo estabelecer um critério universal ou comum para a conduta do homem em todos os campos (ABBAGNANO, 2007, p. 835)

Há o reconhecimento de duas formas de racionalidade: a objetiva, que considera como racional a realidade, o objeto, e a subjetiva, que considera $\mathrm{o}$ homem, o ser que interage com a realidade, como racional (CHAUI, 1997). Na primeira, o foco é no objeto, enquanto na segunda o foco é o ser, o homem.

As decisões vistas como racionais são as que levam ao melhor resultado calculável (RAMOS, 1981). Por isso esta forma de racionalidade é também chamada instrumental ou funcional, pois foca nos resultados que as ações trarão, sua função, a razão como instrumento para alcançar um objetivo.

Críticos à razão instrumental apresentam que esta forma de pensamento faz o homem ser tratado como objeto. "O que não está coisificado, o que não se deixa numerar nem medir, não conta." (ADORNO, 1951, p. 04). Mantêm-se as decisões e ações apenas no campo do cálculo de consequências, não envolvendo valores e sentimentos pessoais. Para Morin (2006), a chamada patologia dessa racionalidade está na hipersimplificação da realidade, que não permite ao indivíduo enxergar a complexidade à sua volta.

Nesse sentido, a racionalidade subjetiva, ou substantiva, é a proposta dos estudiosos sociais para a atualidade, resgatando os conceitos e princípios mais intrínsecos do ser humano. A racionalidade substantiva não diz respeito a uma relação entre meios e fins e não visa objetivos e metas. É a racionalidade que julga de acordo com valores e princípios, não calculando resultados. (RAMOS, 1981)

A racionalidade funcional era uma parte da vida humana associada, porém, na sociedade moderna, esta racionalidade foi amplamente difundida, visando atingir os resultados desejados, principalmente no que diz respeito à esfera financeira e de mercado. O sistema de mercado, que antes tinha sua atuação limitada aos portões das cidades, agora dominava todo o pensa- mento da sociedade e priorizava o cálculo e o ganho. (RAMOS, 1981)

Para melhor compreender os conceitos próprios da Modernidade, mister se faz o entendimento da contraposição que se revela na Pós-Modernidade, resumidamente apresentados no quadro a seguir.

\begin{tabular}{|l|l|}
\hline \multicolumn{1}{|c}{ MoDERNIDADE } & \multicolumn{1}{c|}{ Pós-MODERNIDADE } \\
\hline Linear & Circular \\
\hline Determinista & Voluntarista \\
\hline Homogêneo & Heterogêneo \\
\hline Quantidade & Qualidade \\
\hline Capital & Social \\
\hline Instrumental & Substantiva \\
\hline Reducionismo & Complexidade \\
\hline Mecânico & Orgânico \\
\hline Imposição & Participação \\
\hline
\end{tabular}

Quadro 1: Diferenças entre Modernidade e Pós-Modernidade

Fonte: Adaptado de Chanlat (1996) e de Giddens (1991)

Bauman (2001) afirma que a Modernidade buscou "derreter" os conceitos e estruturas sólidas do tempo pré-moderno para poder instituir novos paradigmas, mais fáceis de explicar, quantificar e, portanto, administrar. Buscando uma sociedade visando apenas os fins, não se importando com os valores éticos $e$ subjetivos do indivíduo.

Já na Pós-Modernidade, período em que muitos teóricos acreditam ter iniciado no século XXI até os dias atuais, reinam outros conceitos, muitos opostos aos vistos acima. Um dos conceitos fortes e latentes na Pós-Modernidade é a complexidade, que considera todas as dimensões da realidade. O pensamento complexo permite a consideração de diversas vertentes da vida humana. Segundo Morin e Le Moigne (2000, p. 199), o pensamento clássico foi fundado sobre três pilares: "a ordem, a separabilidade, a razão". A realidade, porém, se mostra mais ampla e sistêmica do que os princípios acima permitem compreender. Dessa forma, o pensamento complexo surge para complementar o pensamento clássico, da Modernidade.

A maior diferença entre a Modernidade e a PósModernidade reside no impacto do mercado na vida da sociedade. Na Modernidade toda a sociedade é cen- 
trada no mercado, funcional, instrumental e capitalista. Já na Pós-Modernidade, valorizam-se outros setores da vida, por meio de conceitos como pluralidade, circularidade e multiplicidade, permitindo-se outros formatos de organização social e descentralizando as atenções e fontes de comportamentos.

Segundo Sen (apud PEGORARO, 2006), os meios e os fins estão invertidos: os valores fundamentais, os seres humanos e as referências éticas, são substituídos por valores secundários, como produção, renda e lucro. Para Chanlat (1996), a obsessão pela produtividade e sucesso nas organizações leva as mesmas e os pesquisadores organizacionais a não se preocuparem com as atitudes dos seres humanos, mas em focarem seus esforços em técnicas de controle de comportamento. O prelado da produtividade exacerba o controle e, em maior ou menor grau, traduz a conduta e o padrão ético das organizações.

Essa forma de ética, chamada utilitarista, criou uma necessidade nos indivíduos, de sucesso e lucro, que os impele a buscar cada dia mais capital, tornandose parte de sua vida e deixando-os incapazes de decidir e escolher outra possibilidade.

A busca pelo sucesso funcional, financeiro e econômico faz dos valores organizacionais uma ferramenta de modelagem e controle do comportamento desejado. Conceitualmente, crenças e valores organizacionais "[...] são a essência da filosofia daquela organização para atingir o sucesso." (BOWDITCH; BUONO, 2002, p. 185). Esses valores são, muitas vezes, expressados em compromissos da organização, que são a "[...] escolhas que dirigem a conduta [...]" (ABBAGNANO, 2007) dos colaboradores, a eles submetidos sob pena dos mecanismos de controle e punição. Embora o indivíduo tenha o desejo de agir de certa forma, seu comportamento poderá ser completamente diferente, dependendo da pressão da organização e do grupo. (JUDSON, 1980)

Busca-se uma integração total do indivíduo à organização, o que não é possível, pois a racionalidade substantiva dos homens não segue requisitos de eficiência pura e simplesmente, é composta de requisitos mais profundos e valorativos. Não há espaço, nesse pensamento, para a atualização humana, pois o indivíduo não realiza suas potencialidades, mas as da organização. Para Ramos (1981, p. 99):
Há uma tensão contínua entre os sistemas organizacionais planejados e os atualizadores, $e$ afirmar que o indivíduo deveria esforçar-se para eliminar essa tensão, chegando assim a uma condição de equilibro orgânico com a empresa, corresponde a recomendar a deformação da pessoa humana. Somente a um ser deformado pode encontrar em sistemas planejados o meio adequado à própria atualização.

Essa "deformação" do ser humano ocorre desde sua socialização no mundo empresarial. Quando o indivíduo inicia sua atividade laboral é abraçado por novos vocabulários e significados que lhe moldam para o comportamento desejado pela organização. (RAMOS, 1981)

A relação entre o desejo do indivíduo, seus impulsos e valores mais intrínsecos e a razão utilitária das organizações revelam certa tensão. Kant (1995) reconhece que a natureza humana, muitas vezes, deseja o que a razão não pode permitir que seja feito, portanto, são necessários os deveres, ou seja, os imperativos que guiam as ações dos indivíduos para o exercício da virtude, pensando em âmbito universal, não apenas individual. Kant (BARROS, 2006) afirma que a vontade - a paixão - precisa ser controlada pela razão, para que não seja afetada por inclinações particulares, mas respeitando princípios maiores, uma lei moral, por exemplo.

Para Ramos (1981), utilizando os conceitos de Kant, em prol de uma melhora material, o indivíduo perdeu o senso pessoal e de auto-orientação para agir de acordo com seus interesses e fazendo o cálculo utilitário de suas ações. Essa coação racional utilitária "[...] impõe limites à livre e genuína comunicação entre os seres humanos [...]" (RAMOS, 1981, p. 13), na medida em que a ordem da sociedade só é possível quando os indivíduos regulam e limitam suas paixões para não ameaçarem seus interesses.

Essa tensão tende a ser observada na figura dos gestores das organizações, como proposto por esta pesquisa, ratificando algum grau de coerência ou convergência entre a proposta de ética organizacional expressa na declaração institucional e o modelo de ética pessoal, possibilitando associar o paradigma ético praticado a uma perspectiva de Modernidade e Pós-Modernidade. 


\section{Procedimentos Metodológicos e Caracterização da Amostra}

O estudo se caracteriza como uma pesquisa de natureza qualitativa, que segundo Richardson (1999) é uma opção quando se deseja investigar e entender a natureza de um fenômeno. Também se caracteriza como exploratória e descritiva, pois tem como principal finalidade, segundo Gil (1999, p. 42), “[...] proporcionar visão geral, de tipo aproximativo, acerca de determinado fato [...]" e se refere à observação $e$ descrição dos fenômenos, permitindo classificá-los, correlacionando fatos sem a necessidade de manipulá-los, colhendo-os da própria realidade. (CERVO; BERVIAN, 2002)

A unidade de análise desta pesquisa é a organização formal e o objeto de estudo são as organizações vencedoras do Prêmio Catarinense de Excelência (PCE), no período de 2006 a 2010. Nesse período, o PCE reconheceu 17 organizações em Santa Catarina, destas, três são do segmento industrial, cada uma de um porte diferenciado, sendo:

\begin{tabular}{|c|c|c|c|}
\hline $\begin{array}{l}\text { ORGA- } \\
\text { NIZAÇÃo }\end{array}$ & Porte & Ciclo & Nível \\
\hline $\mathrm{O} 1$ & $\begin{array}{l}\text { Pequena } \\
\text { Empresa }\end{array}$ & 2008 & $\begin{array}{l}\text { Compromisso com } \\
\text { a Excelência }\end{array}$ \\
\hline $\mathrm{O} 2$ & $\begin{array}{l}\text { Média } \\
\text { Empresa }\end{array}$ & 2009 & $\begin{array}{l}\text { Compromisso com } \\
\text { a Excelência }\end{array}$ \\
\hline $\mathrm{O} 3$ & $\begin{array}{l}\text { Grande } \\
\text { Empresa }\end{array}$ & 2010 & $\begin{array}{l}\text { Compromisso com } \\
\text { a Excelência }\end{array}$ \\
\hline
\end{tabular}

Quadro 2: Indústrias reconhecidas no PCE de 2006 a 2010 Fonte: Adaptado de Movimento Catarinense para Excelência (2011)

Trata-se de uma amostra não probabilística, pois as empresas são consideradas referência no Estado, sendo reconhecidas por sua gestão, de acordo com o Modelo de Excelência da Gestão. Estas organizações foram selecionadas para o estudo por refletir os três portes de uma categoria representativa em Santa Catarina, o segmento industrial.

Para conhecer as percepções dos gestores das organizações pesquisadas, foi utilizada a técnica de entrevista em profundidade, tendo sido elaborado um roteiro de entrevista foram considerados duas aspectos centrais para fins de análise: (1) o papel da organização na definição de padrões de conduta e (2) a tensão entre a ética do indivíduo e os padrões da organização. Os indicadores considerados no nível 1 foram usados para avaliar o discurso organizacional e os do nível 2, para compreender a percepção dos gestores.

\section{Apresentação e Discussão dos Resultados}

Após a análise das entrevistas e dos documentos, levantaram-se palavras-chave (BARDIN, 2004) e, a partir delas, foi construída a estrutura de relações a seguir, representando como funciona o processo de construção do comportamento desejado, a sua expressão nos documentos e o controle.

Em todas as organizações estudadas, verificou-se que a Liderança determina os Valores ou os Princípios, com base em sua opinião (no caso das $\mathrm{O} 1$ e $\mathrm{O} 2$, que são empresas de pequeno e médio porte) ou nos valores e nos princípios do grupo (no caso da O3). Esses valores dão origem aos Compromissos com as partes interessadas, expressos nos documentos formais da organização.

Para cumprir esses compromissos, as organizações formalizam os Deveres dos colaboradores, incluindo os vindos da regulação trabalhista. Estão bem claras nos documentos as proibições à conduta do colaborador, o que não lhe é permitido fazer, como não se deseja que aja. Essa postura de padronização e regulação reforça o descrito por Foucault (2005), quando afirma que a disciplina busca reger a multiplicidade das pessoas.

Estão explícitos os mecanismos para o controle da transgressão das proibições, via denúncia dos colegas, apuração pelo Comitê de Ética (no caso da O3) e supervisão direta. As transgressões levam à punição, no caso das transgressões às questões da legislação trabalhista, estão previstas e expressas as sanções disciplinares, como advertências, verbais ou escritas, suspensão e demissão por justa causa. Para as demais transgressões não são explícitas as punições cabíveis. O fato de não estar descrito não significa que elas não ocorram. Durante as entrevistas, percebeu-se a clareza com que os gestores concebem as punições relativas às transgressões das regras e normas de conduta estipuladas. 


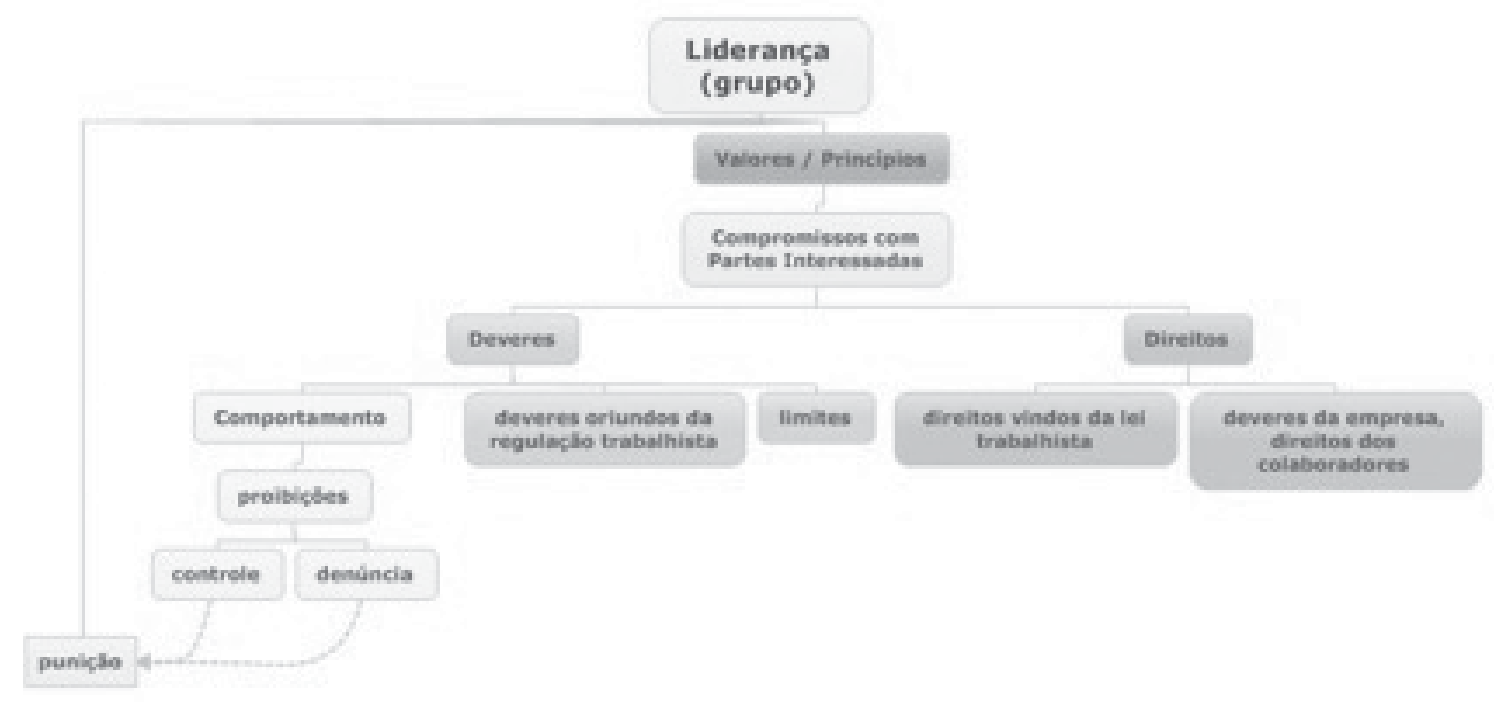

Figura 1: Comportamento e controle

Fonte: Elaborada pelos pesquisadores com base na coleta de dados (2011)

Por outro lado, os documentos também mostram os direitos dos colaboradores, evidenciando quais são os deveres da empresa para com eles e quais os benefícios que a lei trabalhista lhes traz. Destaca-se neste caso a O3, que apresenta os deveres da empresa bem claramente, seus compromissos não só com os colaboradores, mas as outras partes interessadas também.

Durante as entrevistas foram questionados sobre diversos tópicos. Sobre o conceito de ética, foi perguntado aos entrevistados "O que é ética para você". Para o gestor da O1, ética é: "Justiça - conjunto de valores: verdade, ajudar quem precisa, compreender" (Gestor O1.) Nota-se que são muitos conceitos que o gestor tenta resumir em "justiça": valores, verdade, solidariedade, empatia. A ética da justiça é um conceito preconizado por Aristóteles (2007) e reconduzido pelos filósofos cristãos (PEGORARO, 2006). Os conceitos expressos pelo gestor da $\mathrm{O} 1$ também constam nas éticas aristotélica e cristã, pois trata de virtudes (valores), bem comum (solidariedade), busca da verdade e a máxima de se colocar no lugar dos outros (empatia).

Para o gestor da O2, ética é: "[...] saber lidar com empresas, pessoas, associações de classe, sociedade, de forma transparente, pura e clara, de acordo com determinados princípios" (Gestor O2). Aqui nota-se novamente a presença e importância dos valores/ princípios, mas o foco é no relacionamento entre as pessoas, demonstrando maior racionalidade: "saber lidar". Dessa forma, a visão de ética do gestor da $\mathrm{O} 2$ se aproxima da visão kantiana de ética, na qual o princípio coordena a ação, de acordo com a reflexão do homem sobre como agir (SILVA, 1993), buscando, no caso do gestor da $\mathrm{O} 2$, agir de forma transparente, pura e clara com todas as partes interessadas. A resposta deste gestor tem um aspecto mais organizacional do que a resposta do Gestor O1.

Ainda mais sucinto e direto, o gestor da O3 limitou-se a dizer: "Respeito" (Gestor O3). Com apenas uma palavra ele resume o que é ética, na sua visão. Explorando esta palavra, vemos que tem mais relação também com a ética kantiana, pois o respeito nasce da razão. Segundo o dicionário de filosofia Abbagnano (2007), respeito é o reconhecimento da própria dignidade e do outro, agindo de acordo com essa consciência. Na ética kantiana, o respeito é um sentimento moral, produzido pela razão.

Sobre a importância da ética para as organizações, o gestor da $\mathrm{O} 1$ afirmou que "é fundamental para a sobrevivência das empresas, as que não agem com ética estão comprometendo seu futuro" (Gestor O1). Demonstra, durante a entrevista, que acredita ser a ética um novo filtro da seleção natural das organizações. Para ele, as organizações que agem com ética em seus relacionamentos têm muito mais chances de perdurar e manter parcerias do que as organizações 
que não cumprem seus deveres e não apresenta uma postura ética.

Já o gestor da $\mathrm{O} 2$ considera que: "a credibilidade (técnica, atendimento, competência) é um fator de muita relevância dentro das empresas. Se não alinhar as condutas pessoais de cada colaborador com o estilo da empresa e o que se quer, tem-se muito mais a perder no conjunto" (Gestor O2). Na afirmação do gestor, notam-se claramente aspectos da racionalidade funcional: ele vê a ética como geradora de credibilidade, ou seja, analisando o resultado, o objetivo de se preocupar com a ética; afirma que é necessário alinhar as condutas pessoais ao que a empresa deseja, demonstrando o que Ramos (1981) chama de síndrome comportamental, buscando integrar o ser humano à organização.

O gestor da O3 é enfático: "Muito importante, são os limites da conduta" (Gestor O3). Esses limites, ele explica durante a entrevista, são os princípios $e$ valores do grupo da organização, que norteiam $e$ demarcam a conduta desejada pelos colaboradores. Esse posicionamento evidencia uma dissonância entre o conceito de moral e ética, pois, segundo Kant (1995), a moral determina as leis de conduta e a ética examina essas leis.

Quando perguntados se as responsabilidades que pesam sobre o executivo, em suas atribuições no dia a dia, afetam suas decisões ou causam desconforto ao seu estilo de vida, as respostas foram parecidas, em resumo: impacta, mas o gestor escolhe seu próprio caminho. Pode-se afirmar isto a partir das declarações dos gestores: "Todas as decisões geram impacto pessoal (positivo ou negativo) [...] o executivo tem mais liberdade para exercer sua ética" (Gestor O1). Para o gestor da O1, cada executivo escolhe o caminho a seguir, estando ciente das consequências para ele e para a organização, $e$ pode agir mais com base em seus valores pessoais do que os colaboradores, que cumprem as normas estabelecidas.

Já o gestor da $\mathrm{O} 2$ confessa: "Às vezes sinto remorso de alguma decisão, mas depois olho para trás e vejo que foi o melhor a fazer naquela hora" (Gestor $\mathrm{O} 2)$. Mostra, assim, a fragilidade humana diante de uma decisão organizacional. Como afirma Simon (2009), não é possível conhecer todas as variáveis para calcular as consequências de uma decisão, pois a racionalidade funcional é limitada. Assim, o gestor da $\mathrm{O} 2$ afirma que sente por algumas decisões, mas após passar a "emoção", enxerga com os olhos da razão e analisa que foi o melhor a fazer, melhorando a sensação de desconforto.

O gestor da O3 apresenta seu modo de agir: "Em decisões complicadas, viso o bem comum acima de tudo. Não foco só na rentabilidade, mas no desenvolvimento das pessoas, colaboradores e outras que interajam. A ideia é compatibilizar o bem financeiro com o bem das pessoas" (Gestor O3). Nota-se que, apesar de ser presidente de uma grande empresa, que faz parte de um grupo multinacional, o foco, pelo menos para este gestor, é conciliar os resultados financeiros com o "bem das pessoas". O gestor não fala sobre si nesta resposta, sobre algum desconforto gerado, mas mostra a postura de um colaborador no cargo de presidente: fazer o melhor para a equipe e para a empresa.

Questionados sobre se houve alguma situação em que foi necessário interferir no comportamento de algum colaborador, com relação à ética. O gestor da O1 afirmou que já teve questões éticas a serem tratadas com fornecedores, principalmente, que tentam oferecer produtos sem Nota Fiscal, mas sempre negocia com eles para fazer a coisa certa, "pois você faz uma coisa errada e perde todas as coisas certas que já fez" (Gestor O1). Um ponto interessante em sua resposta é que a preocupação não é com o cumprir o dever, como afirma Kant (1995), mas o efeito que a ação incorreta tem sobre a visão do mercado, ou seja, qual a utilidade da mesma, demonstrando fortes traços da ética utilitarista. (SINGER, 2000)

Já o gestor da $\mathrm{O} 2$ informou que nunca precisou interferir no comportamento de algum colaborador ou parte interessada com relação à ética, mas pode ser que tenha ocorrido entre os representantes de vendas (100\% do relacionamento com os clientes é realizado por meio deste serviço), mas não fica sabendo e todos os problemas são remetidos pelos clientes e resolvidos com a rescisão dos contratos, uma vez que os representantes de venda são terceirizados. Reforça aqui sua postura de que certos comportamentos são incorrigíveis, preferindo trocar o profissional a se esforçar para enquadrá-lo no comportamento desejado.

O gestor da $\mathrm{O} 3$ afirmou que há na empresa um Comitê de Ética que avalia os casos de transgressões, quando os casos chegam até o executivo, busca ouvir todos os lados e analisar com cautela, mas afirma que "Se não fizer nada, o exemplo que passa é ruim. 
Punir mostra que ética é importante para nós" (Gestor O3). Essa declaração reforça o que Comte-Sponville (1999) afirma, de que a socialização é realizada por meio da apresentação de normas, proibições e punições, mostrando o que é "feio ou faz mal". A segunda intenção expressa pelo gestor, de mostrar que a ética é importante, reforça o comportamento desejado pela organização, como uma forma de comunicação pelos atos e ritos (de punição), fazendo com que os colaboradores comportem-se como desejado, como um ato de prudência, para evitar a punição. (ROUSSEAU, 2000)

Questionados sobre a convergência entre os objetivos pessoais do executivo e os objetivos da organização, as respostas dos gestores foram bastante diferentes, fato interessante e talvez explicado pela diferença no porte das organizações. O gestor da O1, empresa de pequeno porte, afirmou que os objetivos combinam perfeitamente, já o gestor da $\mathrm{O} 2$, empresa de médio porte, disse que às vezes, por se tratar de uma empresa familiar, tem algumas tensões e conflitos, pois pessoalmente gostaria de beneficiar os familiares em situações do cotidiano, mas precisa de um distanciamento para agir como presidente da empresa $e$ tentar ser mais justo com os colaboradores em geral, causando possíveis problemas com os familiares. Já o executivo da O3, uma multinacional da qual ele é colaborador, afirma que os limites das ações de todos, inclusive as suas, são os princípios éticos do grupo ao qual a organização pertence, não considerando seus objetivos pessoais como influenciadores de sua ação.

Isso se confirma na análise dos documentos, pois os documentos da $\mathrm{O} 1$ focam na força da hierarquia e como os colaboradores devem respeitar e executar as ordens da direção com foco no cliente. Nos documentos da $\mathrm{O} 2$, o foco é na regra em geral, citando legislação trabalhista e muitas regras e proibições normativas, ou seja, buscando tratar a todos como iguais na empresa. Já os documentos da O3 mostram a força da influência do grupo multinacional na unidade avaliada, pois os valores e princípios do grupo são citados amplamente, corroborando o que foi expresso pelo gestor.

Ao final da entrevista, a palavra ficou livre para considerações e complementações, que possibilitaram aos gestores resumirem seu posicionamento sobre o tema. Para o gestor da O1: "Existem várias formas de se fazer as coisas, mas as pessoas preferem fazer do jeito errado e desestimula as que estão no caminho certo" (Gestor O1). Sua afirmação é baseada em sua concepção de que, como empresário de pequeno porte, as barreiras para ser ético e correto são grandes, tendo um esforço maior para fazer agir corretamente do que para fazer o contrário. Durante a entrevista afirmou que não é fácil pagar todos os impostos e agir dentro da lei, mas que se esforça para não descumprir essas normas, pois sabe que é o certo a fazer, mas que o mercado não prioriza isso e não valoriza a empresa mais ética, pelo menos não no contexto brasileiro atual.

As declarações finais do gestor da $\mathrm{O} 2$ também reforçam seu posicionamento durante a entrevista, de um conflito entre a razão e a emoção, o individual $e$ o pessoal, mas sua busca por conciliar estes pontos, demonstrando maior sensibilidade no trato com as pessoas e consigo mesmo: "O comportamento das pessoas e os relacionamentos não têm fórmula, não é matemático, tem emoção, razão, sentimentos, tudo junto para lidar. Precisa ter sensibilidade e criatividade para tratar com as pessoas" (Gestor O2).

O gestor da $\mathrm{O} 3$ finaliza seu posicionamento valorizando o grupo ao qual a organização pertence: "É importante seguir os valores e princípios do grupo da empresa e tomá-los como limite para nossas ações." (Gestor O3). Reforça sua postura de colaborador, que busca exemplarmente cumprir o comportamento desejado, inclusive para poder cobrá-lo de seus subordinados.

As respostas pessoais e os posicionamentos expressos nas entrevistas, principalmente no que tange ao tamanho da organização e a relação contratual entre o gestor e a mesma, são confirmadas na análise dos documentos que expressam os comportamentos desejados pelas organizações, bem como suas diretrizes.

A partir desse fluxo, percebe-se que as organizações avaliadas mantém sua gestão, pelo menos no ponto de vista do comportamento ético, sob os paradigmas da Modernidade, não demonstrando características Pós-Modernas. O quadro abaixo resgata os conceitos de Modernidade e Pós-Modernidade apresentados por Chanlat (1996) e Giddens (1996), destacando os evidenciados pelos documentos analisados e entrevistas realizadas. 


\begin{tabular}{|c|c|c|}
\hline MODERNIDADE & Pós-ModERNIDADE & EVIDÊNCIAS \\
\hline Linear & Circular & Fluxo de pensamentos lógicos lineares, causais: ação-punição \\
\hline Determinista & Voluntarista & $\begin{array}{l}\text { A forma de abordar o comportamento dos colaboradores é de fora para } \\
\text { dentro, ou seja, a organização determina o que espera dos colaboradores e } \\
\text { estes cumprem. Não há abertura para o voluntarismo do colaborador, partindo } \\
\text { dele um comportamento ético. }\end{array}$ \\
\hline Homogêneo & Heterogêneo & $\begin{array}{l}\text { As normas e regras de conduta são uniformes para toda a organização, } \\
\text { fechadas, não havendo a consideração de particularidades pessoais, culturais } \\
\text { ou de personalidade. }\end{array}$ \\
\hline Quantidade & Qualidade & $\begin{array}{l}\text { Do ponto de vista ético, o controle e as punições reforçam a preocupação } \\
\text { com o cumprimento da norma, não o entendimento e a atitude autêntica } \\
\text { dos colaboradores. Ou seja, importa que todos (quantidade) se comportem } \\
\text { como devem, mesmo que não sejam (qualidade) éticos. }\end{array}$ \\
\hline Capital & Social & $\begin{array}{l}\text { O comportamento desejado, expresso nas regras e normas analisadas, serve } \\
\text { aos objetivos traçados pelas organizações, focados no capital. }\end{array}$ \\
\hline Instrumental & Substantiva & $\begin{array}{l}\text { Tanto o fluxo de estabelecimento, controle e punições quanto o discurso } \\
\text { dos gestores, demonstram que a racionalidade instrumental é mais forte nas } \\
\text { organizações estudadas. }\end{array}$ \\
\hline Reducionismo & Complexidade & $\begin{array}{l}\text { A redução da ética à conduta, ao comportamento esperado, não considerando } \\
\text { a complexidade das relações humanas e dos conflitos pessoais, mesmo entre } \\
\text { objetivos pessoais e organizacionais. }\end{array}$ \\
\hline Mecânico & Orgânico & $\begin{array}{l}\text { Estabelecer claramente a conduta esperada, controlar e punir são uma postura } \\
\text { mecânica, lógica, que desconsidera a autenticidade do ser humano. }\end{array}$ \\
\hline Imposição & Participação & $\begin{array}{l}\text { Não há, nas organizações estudadas, a participação dos colaboradores na } \\
\text { discussão e definição dos padrões éticos organizacionais. }\end{array}$ \\
\hline
\end{tabular}

Quadro 3: Conceitos Modernidade e Pós-Modernidade nas Organizações Estudadas

Fonte: Elaborado pela pesquisadora com base na coleta de dados (2011) e adaptado de Chanlat (1996) e Giddens (1991)

As divergências conceituais inerentes a Modernidade e Pós-Modernidade, quando avaliadas no contexto da pesquisa, permitem afirmar que o posicionamento dos executivos das indústrias vencedoras do PCE quanto à dimensão ética, revela-se muito consistente na Modernidade.

\section{Conclusões}

A pesquisa permitiu verificar certa identidade entre o referencial teórico apropriado e a realidade das organizações estudadas. Percebe-se que a racionalidade instrumental e os conceitos da Modernidade permanecem vivos e atuantes na vida empresarial, pelo menos no contexto das organizaçóes estudadas, e sendo valorizado pelo mercado e pelos práticos da área, concedendo a estas empresas um Prêmio por sua gestão.
Esse reconhecimento por parte da sociedade organizada demonstra que a racionalidade funcional prevalece, visando os fins e o cumprimento das normas, enquanto a substantiva, da reflexão pessoal e ação baseada em valores éticos, por enquanto não está em prática nas organizações e não é cobrada pela sociedade envolvida.

Quanto à ética no contexto organizacional, são evidentes os traços da ética utilitarista, embora haja componentes da ética aristotélica e kantiana no discurso dos gestores. Tanto os documentos, que prescritivamente demonstram o que fazer e o que não fazer e suas consequências, quanto a postura de controle sobre o comportamento dos colaboradores, demonstram, na prática, o que Singer (2000) afirma acerca da ética utilitarista, que considera o resultado dos atos para avaliá-los como bons ou ruins, ou seja, baseada nos interesses. 
Analisando o conjunto dos dados coletados, entrevistas e documentos, identificou-se que o discurso dos executivos converge com o discurso organizacional apresentado nos documentos e declarações, pois ambos colocam os valores e princípios da organização como norteadores das ações individuais, tendo claros os limites da ação e as consequências de suas transgressões. Assim, a percepção a respeito da ética expressa na documentação, por conveniência ou não, atestam uma convergência conceitual com a manifesta pelos gestores das organizações, em seus relatos.

Sobre a coerência entre o discurso organizacional e a percepção dos executivos, nota-se um grau avançado de coerência, porém não completa. A coerência é visível no que tange ao que é importante para a organização: hierarquia e foco no cliente (Organização 1), cumprimento da regra e tratamento uniforme para todos (Organização 2) e força do grupo ao qual a organização pertence (Organização 3). Assim, o código de ética definido pela organização, no que tange a sua expressão, parece refletir uma construção coletiva, ainda que tal não tenha sido constatada.

Porém, durante as entrevistas, os gestores revelaram-se preocupados com a ética, a postura do bom profissional, a primazia dos valores pessoais, entre outras características mais individuais. Nos documentos organizacionais, o estilo de discurso, com exceção da Organização 3, na qual o documento analisado tem uma linguagem mais próxima à linguagem do gestor entrevistado, é mais imperativo, determinando o que deve e o que não deve ser feito e respectivas punições. Neste aspecto, portanto, não há uma coerência, pois a forma de abordagem do tema ética é muito diferente.

Assim, o resultado marcante desta pesquisa enseja a compreensão de que o conteúdo das declarações institucionais relativas aos padrões éticos das indústrias vencedoras do PCE preserva uma forte dimensão utilitarista, o que, ainda que convergente com as manifestações de seus executivos, não guarda coerência completa com o discurso.

Foi possível compreender que o papel desempenhado pelo executivo na gestão das empresas pesquisadas é de tal magnitude que a coerência do discurso se distancia da convergência na defesa do conteúdo das declarações institucionais. Ainda assim, na dimensão substantiva do indivíduo, distante, portanto, do papel exercido na organização, ratificam o disposto nas declarações institucionais, caracterizando o homem organizacional (RAMOS, 1981), mesmo na vida social.

\section{RefERÊNCIAS}

ABBAGNANO, N. Dicionário de filosofia. São Paulo: Martins Fontes, 2007.

ADORNO, T. W. Mínima moralia. Reflexionen aus dem beschãdigten leben. Tradução de Artur Morão. Lisboa, Portugal: Edições 70, 1951.

ARISTÓTELES. A política. Coleção a obra-prima de cada autor, n. 61. São Paulo: Martin Claret, 2007.

BARDIN, L. Análise de conteúdo. 3. ed. Tradução de Luís Antero Reto e Augusto Pinheiro. Lisboa: Edições 70, 2004.

BARROS, J. R. A consumação do progresso: sobre a ética e a filosofia da história kantiana. Cadernos de Ética e Filosofia Política 9, p. 41-58, 2/2006.

BAUMAN, Z. Modernidade líquida. Tradução de Plínio Dentzien. Rio de Janeiro, RJ: Jorge Zahar Editor Ltda., 2001.

BOFF, L. Ética e moral: a busca de fundamentos. Petrópolis, RJ: Vozes, 2003.

BOWDITCH, J. L.; BUONO, A. F. Elementos do comportamento organizacional. São Paulo: Pioneira, 2002.

\section{CARVALHO, M. C. B. Comportamento}

organizacional: uma análise em função da prática de gestão segundo a percepção dos dirigentes industriais - um estudo multicaso. Dissertação de Mestrado. UDESC/ESAG Curso de Mestrado em Administração. Florianópolis, 2005.

CERVO, A. L.; BERVIAN, P. A. Metodologia científica. 5. ed. São Paulo: Pearson Prentice Hall, 2002.

\section{CHANLAT, J-F. O indivíduo na organização:}

dimensões esquecidas. Vol III. 3. ed. São Paulo: Atlas, 1996.

CHAUI, M. Filosofia. 8. ed. São Paulo: Ática, 1997. 


\section{COMTE-SPONVILLE, A. Pequeno tratado das}

grandes virtudes. São Paulo: Martins Fontes, 1999.

FOUCAULT, M. Em defesa da sociedade. Curso no College de France (1975-1976). Tradução de Maria Ermantina Galvão. São Paulo: Martins Fontes, 2005.

GIL, A. C. Métodos e técnicas de pesquisa social.

6. ed. São Paulo: Atlas, 2008.

GIDDENS, A. As consequências da Modernidade. Tradução de Raul Fiker. São Paulo: Editora UNESP, 1991.

JUDSON, A. S. Relações humanas e mudanças organizacionais. São Paulo: Atlas, 1980.

KANT, I. A religião nos limites da simples razão. Tradução de Artur Morão. Lisboa: Edições 70, 1992.

Crítica da razão pura. Tradução de J.

Rodrigues de Merege. São Paulo: Ediouro, 1995.

Movimento Catarinense para Excelência (MCE).

Critérios rumo à excelência. Florianópolis: 2009.

Regulamento do prêmio catarinense de

excelência 2010. Florianópolis: 2010.

Informações sobre ciclos anteriores

do Prêmio Catarinense de Excelência. [2011].

Disponível em: <www.excelenciasc.org.br>. Acesso em:

25 mar. 2011.

MENDONÇA, K. Deus e diabo nos detalhes: a ética em Buber e Adorno. Lua Nova. Revista de Cultura e

Política, São Paulo, n. 60, p. 117-129, 2003.

MORIN, E.; LE MOIGNE, J. L. A Inteligência da

Complexidade. São Paulo: Petrópolis, 2000.

MORIN, E. Introdução ao pensamento complexo.

Tradução do francês Eliane Lisboa. Porto Alegre: Sulina, 2006.

PEGORARO, O. Ética dos maiores mestres através da história. Petrópolis, RJ: Vozes, 2006.

RAMOS, A. G. A nova ciência das organizações: uma reconceituação da riqueza das nações. Tradução de Mary Cardoso. Rio de Janeiro: Fundação Getúlio Vargas, 1981.
Modelos de homem e teoria administrativa.

Cadernos Monográficos PUC-PR, 2001.

RICHARDSON, R. J. Pesquisa social: métodos e técnicas. São Paulo: Atlas, 1999.

ROUSSEAU, J. J. Do contrato social. São Paulo: Edipro, 2000.

SILVA, F. L. Breve panorama histórico da ética. Revista Bioética, Brasília, v. 1 n. 1, 1993.

SIMON, H. Modelo comportamental de decisão racional. Tradução de Francisco G. Heidemann. In: HEIDEMANN, F. G.; SALM, J. F. Políticas públicas e desenvolvimento: bases epistemológicas e modelos de análise. Brasília: Editora Universidade de Brasília, 2009.

SINGER, P. Ética prática. Tradução de Álvaro Augusto Fernandes. Lisboa: Gradiva, 2000. 